\title{
Author Spotlight: Noemi Zorzetti
}

\section{Noemi Zorzetti ${ }^{1}$}

Accepted: 28 January 2021 / Published online: 21 February 2021

(C) The Author(s), under exclusive licence to Springer Science+Business Media, LLC part of Springer Nature 2021

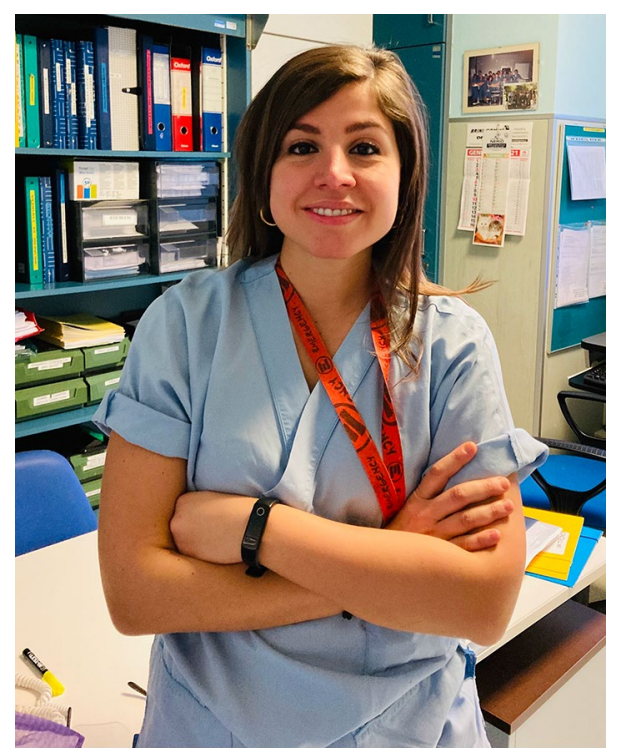

Noemi Zorzetti received her medical degree from the University of Napoli-Federico II in 2011, specializing in General Surgery in July 2018 at St. Orsola University Hospital in Bologna, Italy. She is working as an attending surgeon in the Department of General Surgery at the "Ospedale Civile Umberto I," Lugo, Ravenna, Italy. She is interested in emergency surgery and is also involved in the treatment of hernias and in abdominal wall surgery.

Publisher's Note Springer Nature remains neutral with regard to jurisdictional claims in published maps and institutional affiliations.

Noemi Zorzetti

noemi.zorzetti@gmail.com

1 Department of General Surgery, "Ospedale Civile Umberto I” Hospital, Lugo, Ravenna, Italy 